\title{
Low parathyroid hormone level predicts infection-related mortality in incident dialysis patients: a prospective cohort study
}

Yu Ah Hong ${ }^{1}$, Jeong Ho Kim ${ }^{1}$, Yong Kyun Kim¹, Yoon Kyung Chang ${ }^{1}$, Cheol Whee Park ${ }^{1}$, Suk Young Kim¹, Yon Su Kim ${ }^{2,3}$, Shin-Wook Kang ${ }^{3,4}$, Nam-Ho Kim ${ }^{3,5}$, Yong-Lim Kim ${ }^{3,6}$, and Chul Woo Yang ${ }^{1,3}$

\begin{abstract}
${ }^{1}$ Department of Internal Medicine, College of Medicine, The Catholic University of Korea, Seoul; ${ }^{2}$ Department of Internal Medicine, Seoul National University College of Medicine, Seoul; ${ }^{3}$ Clinical Research Center for End Stage Renal Disease, Daegu; ${ }^{4}$ Department of Internal Medicine, Yonsei University College of Medicine, Seoul; ${ }^{5}$ Department of Internal Medicine, Chonnam National University Medical School, Gwangju; ${ }^{6}$ Department of Internal Medicine, Kyungpook National University Hospital, Daegu, Korea
\end{abstract}

\author{
Received: July 15, 2018 \\ Revised : September 3, 2018 \\ Accepted: October 4, 2018

\section{Correspondence to} \\ Chul Woo Yang, M.D. \\ Division of Nephrology, \\ Department of Internal Medicine, \\ College of Medicine, Seoul St. \\ Mary's Hospital, The Catholic \\ University of Korea, 222 Ban- \\ po-daero, Seocho-gu, Seoul 06591, \\ Korea \\ Tel: +82-2-2258-6851 \\ Fax: +82-2-2258-6879 \\ E-mail:yangch@catholic.ac.kr
}

Background/Aims: Parathyroid hormone (PTH) is an important factor influencing immunologic dysfunction, but the effect of PTH level on infection-related outcomes remains unclear in incident dialysis.

Methods: We evaluated a multicenter prospective cohort study of 1,771 incident dialysis patients (1,260 hemodialysis and 511 peritoneal dialysis) in Korea. Patients were divided into three groups based on serum intact PTH (iPTH) level. The primary outcomes were all-cause and infection-related mortality and multivariate Cox regression analysis was performed to evaluate the role of iPTH in all-cause and infection-related mortality.

Results: During the follow-up period of 27.3 months, 175 patients (9.9\%) died, and infection-related death represented $20 \%$ of all-cause mortality. Both all-cause mortality and infection-related mortality rates $(p<0.001$ and $p=0.003$, by logrank) were markedly higher in patients with serum iPTH $<150 \mathrm{pg} / \mathrm{mL}$ than in the other groups. Multivariate Cox regression analysis revealed that patients with serum iPTH $<150 \mathrm{pg} / \mathrm{mL}$ remained at higher risk for infection-related mortality than patients in the target range of $150 \leq \mathrm{iPTH}<300 \mathrm{pg} / \mathrm{mL}$, after adjusting for confounding variables (hazard ratio [HR], 2.52; 95\% confidence interval, 1.06 to 5.99; $p=0.04$ ). The HR of infection-related mortality in patients with serum iPTH $<150 \mathrm{pg} / \mathrm{mL}$ was significantly higher in patients with low serum phosphorus, low $\mathrm{Ca} \times \mathrm{P}$ product, low serum alkaline phosphatase and those older than 65 years.

Conclusions: Low serum iPTH level is an independent predictor of infection-related mortality in incident dialysis patients.

Keywords: Parathyroid hormone; Infection; Mortality; Dialysis

\section{INTRODUCTION}

A link between intact parathyroid hormone (iPTH) and mortality has been investigated as a biomarker of chronic kidney disease-mineral bone disorder (CKD-MBD) for decades. Most epidemiologic studies reported that higher serum iPTH level is associated with increased all-cause mortality in dialysis patients [1-3]. However, the impact of iPTH level on mortality is controversial in dialysis patients [4-6].

Infectious disease is the second most common cause of mortality in CKD patients [7]. Renal dysfunction is ac- 
companied by disturbances of the immune system and subsequent susceptibility to infections [8]. PTH receptors are located in circulating human lymphocytes and are known as immunoregulatory factors [9]. Thus, PTH may be an important factor influencing immunologic dysfunction, but the roles of PTH in the immune system in dialysis patients remain unclear.

An improved understanding of the role of PTH in infection could lead to identification of preventive and therapeutic targets of CKD-MBD for infection control in dialysis patients. However, there are insufficient data to identify the relationships between infection-related outcomes and serum iPTH level in dialysis patients. Therefore, we performed this study to determine whether serum iPTH level is associated with infection-related outcome in incident dialysis patients through a multicenter prospective observational cohort study in Korea.

\section{METHODS}

\section{Study design}

All patients in this study participated in the Clinical Research Center for End Stage Renal Disease (CRC registry for ESRD). The CRC registry for ESRD is an observational prospective cohort performed in patients with ESRD from 31 medical centers in Korea (Supplementary Material 1). This cohort study started in April 2009 and ended in July 2015. A total of 2,208 incident dialysis patients were enrolled during this period. Incident dialysis patients were defined as newly diagnosed ESRD patients within 3 months of initiating hemodialysis (HD) or peritoneal dialysis (PD). We excluded patients for whom information about the level of iPTH at the time of enrollment was not available $(n=437)$. A total of 1,260 patients (71.1\%) with HD and 511 patients (28.9\%) with PD were included in the final analysis. Although Korean working group recommendations for management of CKD-MBD were recently established, most dialysis patients are managed with therapeutic interventions for CKD-MBD parameters according to Kidney Disease Outcomes Quality Initiative (KDOQI) guidelines in Korea [10]. Therefore, we categorized enrolled patients into three groups based on serum iPTH level at baseline as follows [11]: serum iPTH < 150 pg/mL (low), $150 \leq$ serum iPTH $<300 \mathrm{pg} / \mathrm{mL}$ (target range), and serum iPTH $\geq 300$ $\mathrm{pg} / \mathrm{mL}$ (high). Fig. 1 shows the design and flowchart of participants in this study. Our research protocol was approved by the Institutional Review Board at each center (KC16ONME0595) and performed in accordance with the Declaration of Helsinki. All participants provided informed consent.

\section{Clinical data acquisition}

Demographic and clinical data were collected at the time of study enrollment. Baseline demographic and clinical data were collected from clinical charts and medical histories. Age, sex, body mass index (BMI), causes of ESRD, incidence of diabetes mellitus (DM), hypertension, coronary artery diseases (CAD), malignancy and human immunodeficiency virus (HIV) infection, type of vascular access in $\mathrm{HD}$, type of $\mathrm{PD}$, systolic and diastolic blood pressures (BP), and laboratory investigations were recorded. Blood samples were collected at the time of pre-dialysis in HD and at visit of outpatient clinic in PD from enrolled participants who fasted overnight. Laboratory data were available for hemoglobin, white blood cell (WBC) count, blood urea nitrogen, creatinine, albumin, sodium, potassium, corrected calcium, phosphorus, alkaline phosphatase (ALP), iPTH, total cholesterol, and high-sensitivity C-reactive protein (hs-CRP) from blood samples. The modified Charlson comorbidity index was recorded at the time of dialysis. Each patient's nutrient status was assessed by subjective global assessment (SGA). Serum iPTH level was measured using a radioimmunoassay kit. Serum calcium level was corrected for albumin concentration using the following formula: corrected calcium $=$ measured calcium $+(4-$ measured albumin) $\times 0.8$.

\section{Clinical outcomes}

The primary outcome measures were all-cause and infection-related mortality. All participants were followed until death or the research was terminated, with data censored when a patient underwent renal transplantation or was lost to follow-up because of patient refusal of further participation or transfer to a nonparticipating hospital. Deaths that occurred during the study were reported to study investigators, who identified causes of death according to the research classification system at each clinical center. 


\section{Statistical analysis}

Continuous variables were presented as the mean \pm standard deviation, and categorical variables were presented as number with percentage. Differences among groups for categorical variables were analyzed by Pearson's chisquare test. Continuous data were compared using oneway analysis of variance to detect differences among the three groups. Absolute mortality rate was presented per 100 person-years of follow up. Survival curves for serum iPTH level were estimated by Kaplan-Meier method, and significance of the survival curve was assessed by log rank test. Hazard ratios (HRs) with 95\% confidence intervals (CIs) for all-cause and infection-related mortality were calculated by Cox proportional hazard regression analysis. The Cox proportional hazard regression models were adjusted for known CKD-MBD parameters based on prior studies and clinical insight and significant $(p<0.1)$ predictors for all-cause and infection-related mortality in univariate Cox regression analysis including age, sex, DM, CAD, malignancy, HIV infection, BMI, systolic BP, diastolic BP, modified Charlson comorbidity index, hemoglobin, creatinine, albumin, potassium, corrected calcium, phosphorus, alkaline phosphatase, hs-CRP, and SGA. All statistical analyses were performed using SPSS version 20.0 (IBM Corp., Armonk, NY, USA). A $p<0.05$ was considered to indicate statistical significance.

\section{RESULTS}

\section{Patient characteristics}

The clinical and laboratory characteristics of participants are described in Table 1 . The mean age of enrolled patients was $56.3 \pm 14.3$ years, and $61.1 \%$ were men. Patients with low serum iPTH level (serum iPTH $<150$ $\mathrm{pg} / \mathrm{mL}$ ) were significantly older, had lower BMI, and were more likely to be male and to have DM, CAD, and malignancy than patients with high serum iPTH level (serum iPTH $\geq 300 \mathrm{pg} / \mathrm{mL}$ ). Among causes of ESRD, diabetic renal disease was more common in patients with low serum iPTH level than in those with high serum iPTH level. The prevalence of hypertension and HIV infection, WBC, serum sodium, and total cholesterol levels were not significantly different among the three groups. Patients with low serum iPTH level showed significant- ly lower serum creatinine, serum albumin, serum potassium, serum phosphorus, ALP, and nutritional status compared to patients with high serum iPTH level. Patients with low serum iPTH level had higher Charlson comorbidity index, hemoglobin, corrected calcium, and hs-CRP than patients with high serum iPTH level. The CKD-MBD parameters were assessed to identify the difference of distribution between HD and PD (Table 2). Serum phosphorus, calcium $\times$ phosphorus $(\mathrm{Ca} \times \mathrm{P})$ product, and serum iPTH level did not significantly differ between HD and PD patients, and the proportion of patients with corrected calcium level $<8.4 \mathrm{mg} / \mathrm{dL}$ in HD increased more than in $\operatorname{PD}(p=0.036)$ (Table 2).

\section{Relationship between serum iPTH level and all- cause or infection-related mortality in incident dialysis patients}

The median duration of follow-up was 27.3 months (interquartile range, 8 to 24). During the follow-up period, 723 patients were dropped out from the study for reasons other than death (40.8\% of all patients). One hundred seventy-five deaths were recorded during the study period, and the absolute mortality rate of this study was 4.29 deaths per 100 person-years. The causes of death were cardiovascular disease including sudden cardiac death, myocardial infarction, congestive heart failure, and stroke (55/175, 31.4\%), followed by infection (35/175, $20 \%)$, and other diseases caused by malignancy, liver failure, chronic obstructive lung disease, and others ( $85 / 175$, 48.6\%). All-cause and infection-related mortality were further increased in patients with low serum iPTH level compared to the other groups $(p<0.001$ and $p=0.002)$. However, cardiovascular mortality was not significantly different among the three groups $(p=0.580$ ) (Table 3). Kaplan-Meier curve of survival according to serum iPTH level at baseline is shown in Fig. 2. Patients with low serum iPTH level had poorer survival for both allcause and infection-related death than those with normal or high serum iPTH level $(p<0.001$ and $p=0.003$, respectively, by log rank). On closer inspection, all-cause mortality was considerably increased in patients with low serum iPTH level compared to those with high serum iPTH level $(p<0.001)$, but there was no significant difference between patients with low serum iPTH level and those with serum iPTH level within the target range ( $p=0.086$, by log rank). In contrast, infection-re- 
Table 1. Baseline characteristics of the study population according to the levels of serum iPTH

\begin{tabular}{|c|c|c|c|c|}
\hline Characteristic & iPTH < $150(n=582)$ & $150 \leq \mathrm{iPTH}<300(\mathrm{n}=590)$ & $\mathrm{iPTH} \geq 300(\mathrm{n}=599)$ & $p$ value \\
\hline Intact PTH, pg/mL & $83.4 \pm 42.1^{\mathrm{a}}$ & $218.1 \pm 43.6^{\mathrm{b}}$ & $510.5 \pm 264 \cdot 1^{c}$ & $<0.001$ \\
\hline Age, yr & $59.6 \pm 13.4^{\mathrm{a}}$ & $57.5 \pm 13.8^{b}$ & $52.0 \pm 14.5^{c}$ & $<0.001$ \\
\hline Male sex & $362(62.2)$ & $384(65.1)$ & $336(56.1)$ & 0.005 \\
\hline $\mathrm{BMI}, \mathrm{kg} / \mathrm{m}^{2}$ & $22.0 \pm 5.3^{\mathrm{a}}$ & $22.5 \pm 5.0^{a, b}$ & $22.9 \pm 4.7^{\mathrm{b}}$ & 0.014 \\
\hline $\mathrm{DM}$ & $376(64.6)$ & $368(62.4)$ & $237(39.6)$ & $<0.001$ \\
\hline HTN & $142(24.4)$ & $131(22.2)$ & $153(25.5)$ & 0.392 \\
\hline Coronary artery disease & $89(15 \cdot 3)$ & $82(13.9)$ & $59(9.8)$ & 0.015 \\
\hline Malignancy & $53(9.1)$ & $37(6.3)$ & $26(4 \cdot 3)$ & 0.004 \\
\hline HIV & $6(1.0)$ & $5(0.8)$ & $1(0.2)$ & 0.161 \\
\hline Cause of ESRD & & & & $<0.001$ \\
\hline $\mathrm{DM}$ & $330(56.7)$ & $343(58.1)$ & $214(35 \cdot 7)$ & \\
\hline GN & $73(12.5)$ & $84(14.2)$ & $113(18.9)$ & \\
\hline PCKD & $15(1.6)$ & $12(2.0)$ & $20(3.3)$ & \\
\hline Others/unknown & $164(28.2)$ & $151(25.6)$ & $252(42.1)$ & \\
\hline Modality (HD) & $414(71.1)$ & $426(72.2)$ & $420(70.1)$ & 0.730 \\
\hline Type of vascular access (\% in HD) & & & & $<0.001$ \\
\hline AVF & $66(15.9)$ & $105(24.6)$ & $90(21.4)$ & \\
\hline AVG & $32(7.7)$ & $21(4.9)$ & $8(1.9)$ & \\
\hline HD catheter & $303(73.2)$ & $296(32.3)$ & $316(75.2)$ & \\
\hline Unknown & $13(3.1)$ & $4(0.9)$ & $6(1.4)$ & \\
\hline Type of PD (\% in PD) & & & & 0.604 \\
\hline CAPD & $97(57.7)$ & $91(55.5)$ & $109(60.9)$ & \\
\hline APD & $12(7.1)$ & $17(10.4)$ & $18(10.1)$ & \\
\hline Unknown & $59(35.1)$ & $56(34.1)$ & $52(29.1)$ & \\
\hline Systolic BP, mmHg & $135.2 \pm 35.5^{\mathrm{a}}$ & $141.7 \pm 31.0^{\mathrm{b}}$ & $138.1 \pm 33 \cdot 4^{\mathrm{a}, \mathrm{b}}$ & 0.004 \\
\hline Diastolic BP, mmHg & $73.7 \pm 20.8^{a}$ & $76.3 \pm 18.0^{\mathrm{b}}$ & $77.6 \pm 19.5^{\mathrm{b}}$ & 0.003 \\
\hline Charlson comorbidity index & $5.74 \pm 2.35^{\mathrm{a}}$ & $5.45 \pm 2.33^{\mathrm{b}}$ & $4.38 \pm 2.20^{\mathrm{c}}$ & $<0.001$ \\
\hline WBC, $10^{3} / \mathrm{mm}^{3}$ & $7.0 \pm 3.1$ & $7.0 \pm 3.1$ & $6.9 \pm 3.1$ & 0.914 \\
\hline Hemoglobin, g/dL & $9.1 \pm 1.5^{\mathrm{a}}$ & $8.8 \pm 1.6^{\mathrm{b}}$ & $8.7 \pm 1.8^{\mathrm{b}}$ & 0.001 \\
\hline Urea nitrogen, mg/dL & $75.8 \pm 34.8^{\mathrm{a}}$ & $82.3 \pm 36.0^{b}$ & $91.5 \pm 41.6^{c}$ & 0.001 \\
\hline Serum creatinine, $\mathrm{mg} / \mathrm{dL}$ & $7.4 \pm 3.0^{\mathrm{a}}$ & $8.5 \pm 3.6^{b}$ & $10.2 \pm 5.2^{c}$ & $<0.001$ \\
\hline Serum albumin, g/dL & $3.3 \pm 0.7^{\mathrm{a}}$ & $3.3 \pm 0.6^{\mathrm{a}}$ & $3.5 \pm 0.6^{b}$ & $<0.001$ \\
\hline Serum sodium, mmol/L & $137.0 \pm 5.4$ & $137.3 \pm 0.6$ & $137.6 \pm 4.7$ & 0.119 \\
\hline Serum potassium, $\mathrm{mmol} / \mathrm{L}$ & $4.5 \pm 1.0^{\mathrm{a}}$ & $4.7 \pm 0.9^{b}$ & $4.7 \pm 0.9^{b}$ & 0.001 \\
\hline Corrected calcium, mg/dL & $8.7 \pm 0.9^{\mathrm{a}}$ & $8.3 \pm 0.9^{b}$ & $7.8 \pm 1.1^{\mathrm{c}}$ & $<0.001$ \\
\hline Serum phosphorus, mg/dL & $5.1 \pm 1.7^{\mathrm{a}}$ & $5.6 \pm 1.8^{b}$ & $6.1 \pm 2.2^{c}$ & $<0.001$ \\
\hline Alkaline phosphatase, IU/L & $99.0 \pm 77.9^{\mathrm{a}}$ & $101.1 \pm 80.3^{\mathrm{a}}$ & $113.2 \pm 91.7^{\mathrm{b}}$ & 0.008 \\
\hline Total cholesterol, mg/dL & $160.0 \pm 49.6$ & $156.1 \pm 48.5$ & $158.2 \pm 48.6$ & 0.626 \\
\hline hs-CRP, mg/dL & $7.7 \pm 24.3^{\mathrm{a}}$ & $4.6 \pm 14.9^{\mathrm{b}}$ & $4.0 \pm 13.7^{b}$ & 0.008 \\
\hline
\end{tabular}


Table 1. Continued

\begin{tabular}{|c|c|c|c|c|}
\hline Characteristic & iPTH < $150(n=582)$ & $150 \leq \mathrm{iPTH}<300(\mathrm{n}=590)$ & iP'TH $\geq 300(n=599)$ & $p$ value \\
\hline SGA & $4.92 \pm 2.08^{a}$ & $5.28 \pm 1.86^{\mathrm{b}}$ & $5.31 \pm 1.74^{b}$ & 0.001 \\
\hline Urine output, L/day & $0.62 \pm 0.77$ & $0.70 \pm 0.72$ & $0.65 \pm 0.71$ & 0.215 \\
\hline
\end{tabular}

Values are presented as mean \pm SD or number $(\%)$.

iPTH, intact parathyroid hormone; BMI, body mass index; DM, diabetes mellitus; HTN, hypertension; HIV, human immunodeficiency virus; ESRD, end-stage renal disease; GN, glomerulonephritis; PCKD, polycystic kidney disease; HD, hemodialysis; AVF, arteriovenous fistula; AVG, arteriovenous graft; CAPD, continuous ambulatory peritoneal dialysis; APD, automated peritoneal dialysis; BP, blood pressure; WBC, white blood cells; hs-CRP, high sensitive C-reactive protein; SGA, subjective global assessment.

${ }^{a, b, c}$ The different superscripts denote significant differences between groups not sharing the same superscript at 0.05 level based on Scheffe post hoc test by one-way analysis of variance.

Table 2. The distribution of baseline parameters for CKD-MBD according to KDOQI guidelines in study population

\begin{tabular}{|c|c|c|c|c|}
\hline Variable & Total & Hemodialysis & Peritoneal dialysis & $p$ value \\
\hline Phosphorus, mg/dL & & & & 0.446 \\
\hline$<3.5$ & $208(11.7)$ & $149(11.8)$ & $59(11.5)$ & \\
\hline $3 \cdot 5-5 \cdot 5$ & $746(42.1)$ & $519(41.2)$ & $227(44 \cdot 4)$ & \\
\hline$>5 \cdot 5$ & $817(46.1)$ & $592(47.0)$ & $225(44.0)$ & \\
\hline Corrected calcium, mg/dL & & & & 0.036 \\
\hline$<8.4$ & $848(47 \cdot 9)$ & $625(49 \cdot 6)$ & $223(43.6)$ & \\
\hline $8.4-9.5$ & $800(45.2)$ & $556(44.1)$ & $244(47 \cdot 7)$ & \\
\hline$\geq 9.5$ & $123(6.9)$ & $79(6.3)$ & $44(8.6)$ & \\
\hline $\mathrm{Ca} \times \mathrm{P}$ product, $\mathrm{mg}^{2} / \mathrm{dL}^{2}$ & & & & 0.475 \\
\hline$<55$ & $1487(84.0)$ & $1063(84.4)$ & $424(83.0)$ & \\
\hline$\geq 55$ & $284(16.0)$ & $197(15 \cdot 6)$ & $87(17.0)$ & \\
\hline iPTH, pg/mL & & & & 0.630 \\
\hline$<150$ & $582(32.9)$ & $414(32.9)$ & $168(32.9)$ & \\
\hline $150-300$ & $590(33 \cdot 3)$ & $426(33.8)$ & $164(32.1)$ & \\
\hline$\geq 300$ & $599(33.8)$ & $420(33.3)$ & $179(35.0)$ & \\
\hline
\end{tabular}

Values are presented as number (\%).

CKD-MBD, chronic kidney disease-mineral bone disorder; KDOQI, Kidney Disease Outcomes Quality Initiative; Ca, calcium; P, phosphorus; iPTH, intact parathyroid hormone.

Table 3. Causes of deaths of the study population according to the levels of serum intact PTH

\begin{tabular}{|c|c|c|c|c|c|}
\hline \multirow{2}{*}{ Variable } & \multicolumn{4}{|c|}{ iPTH, pg/mL } & \multirow{2}{*}{$p$ value } \\
\hline & Total & iPTH $<150$ & $150 \leq \mathrm{iPTH}<300$ & iPTH $\geq 300$ & \\
\hline All causes of death & $175(100)$ & $82(46.9)$ & $60(34.3)$ & $33(18.8)$ & $<0.001$ \\
\hline Cardiovascular disease & $55(31.4)$ & $20(36.4)$ & $20(36.4)$ & $15(27.2)$ & 0.580 \\
\hline Infection-related disease & $35(20.0)$ & $21(60.0)$ & $8(22.9)$ & $6(17.1)$ & 0.002 \\
\hline Others & $85(48.6)$ & $41(48.2)$ & $32(37.7)$ & $12(14.1)$ & $<0.001$ \\
\hline
\end{tabular}

Values are presented as number (\%).

iPTH, intact parathyroid hormone. 
Table 4. Univariable and multivariable Cox hazard regression analyses for all-cause and infection-related mortality according to the levels of serum iPTH levels

\begin{tabular}{|c|c|c|c|c|c|c|c|c|c|}
\hline \multirow{2}{*}{ Variable } & \multicolumn{3}{|c|}{ Crude model } & \multicolumn{3}{|c|}{ Model $1^{\mathrm{a}}$} & \multicolumn{3}{|c|}{ Model $2^{b}$} \\
\hline & HR & $95 \% \mathrm{CI}$ & $p$ value & HR & $95 \%$ CI & $p$ value & HR & $95 \% \mathrm{CI}$ & $p$ value \\
\hline \multicolumn{10}{|l|}{ All-cause mortality } \\
\hline iPTH $<150$ & 1.34 & $0.96-1.87$ & 0.09 & 0.81 & $0.58-1.13$ & 0.22 & 1.1 & $0.74-1.61$ & 0.65 \\
\hline $150 \leq \mathrm{iPTH}<300$ & \multicolumn{3}{|c|}{1 (reference) } & \multicolumn{3}{|c|}{1 (reference) } & \multicolumn{3}{|c|}{1 (reference) } \\
\hline $\mathrm{iPTH} \geq 300$ & 0.53 & $0.35-0.81$ & 0.003 & 0.68 & $0.44^{-1.05}$ & 0.08 & 0.95 & $0.58-1.58$ & 0.87 \\
\hline \multicolumn{10}{|c|}{ Infection-related mortality } \\
\hline $\mathrm{iPTH}<150$ & 2.61 & $1.16-5.89$ & 0.02 & 2.61 & $1.16-5.89$ & 0.02 & 2.52 & $1.06-5.99$ & 0.04 \\
\hline $150 \leq \mathrm{iPTH}<300$ & \multicolumn{3}{|c|}{1 (reference) } & \multicolumn{3}{|c|}{1 (reference) } & \multicolumn{3}{|c|}{1 (reference) } \\
\hline $\mathrm{iPTH} \geq 300$ & 0.73 & $0.25-2.10$ & 0.55 & 0.92 & $0.31-2.74$ & 0.89 & 1.08 & $0.31-3.74$ & 0.90 \\
\hline
\end{tabular}

iPTH, intact parathyroid hormone; HR, hazard ratio; CI, confidence interval.

${ }^{a}$ Model 1: Multivariate model including age and sex.

${ }^{b}$ Model 2: Multivariate model including model 1 + diabetic mellitus, coronary artery diseases, malignancy, human immunodeficiency virus infection, body mass index, systolic blood pressure, diastolic blood pressure, modified Charlson comorbidity index, hemoglobin, creatinine, albumin, potassium, corrected calcium, phosphorus, alkaline phosphatase, high sensitive C-reactive protein, and subjective global assessment.

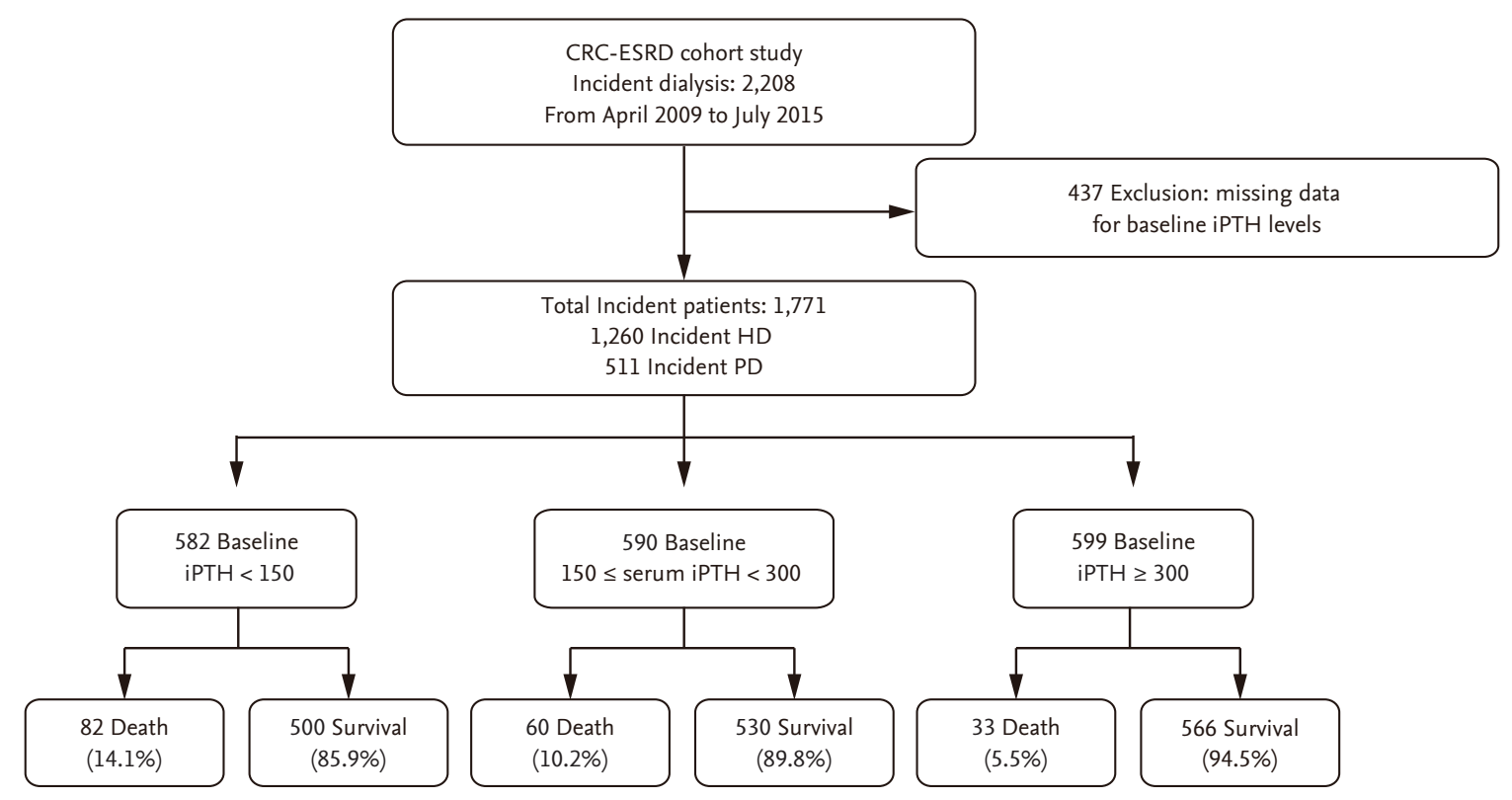

Figure 1. Study design and flow chart of study participants. CRC-ESRD, Clinical Research Center for End Stage Renal Disease; iPTH, intact parathyroid hormone; HD, hemodialysis; PD, peritoneal dialysis.

lated mortality was substantially increased in patients with low serum iPTH level compared to both those with high or within the target range of serum iPTH level $(p$ $=0.003$ or $p=0.013$, respectively, by log rank test) (Fig. 2). The causes of death by infection were respiratory infection including pneumonia (19/35, 54.3\%), sepsis of unknown origin $(11 / 35,31.4 \%)$, gastrointestinal infection $(2 / 35,5.8 \%)$, and other causes $(3 / 35,8.7 \%)$.

\section{Effects of serum iPTH level on all-cause and infec- tion-related mortality}

Table 4 shows univariable and multivariable Cox hazard 

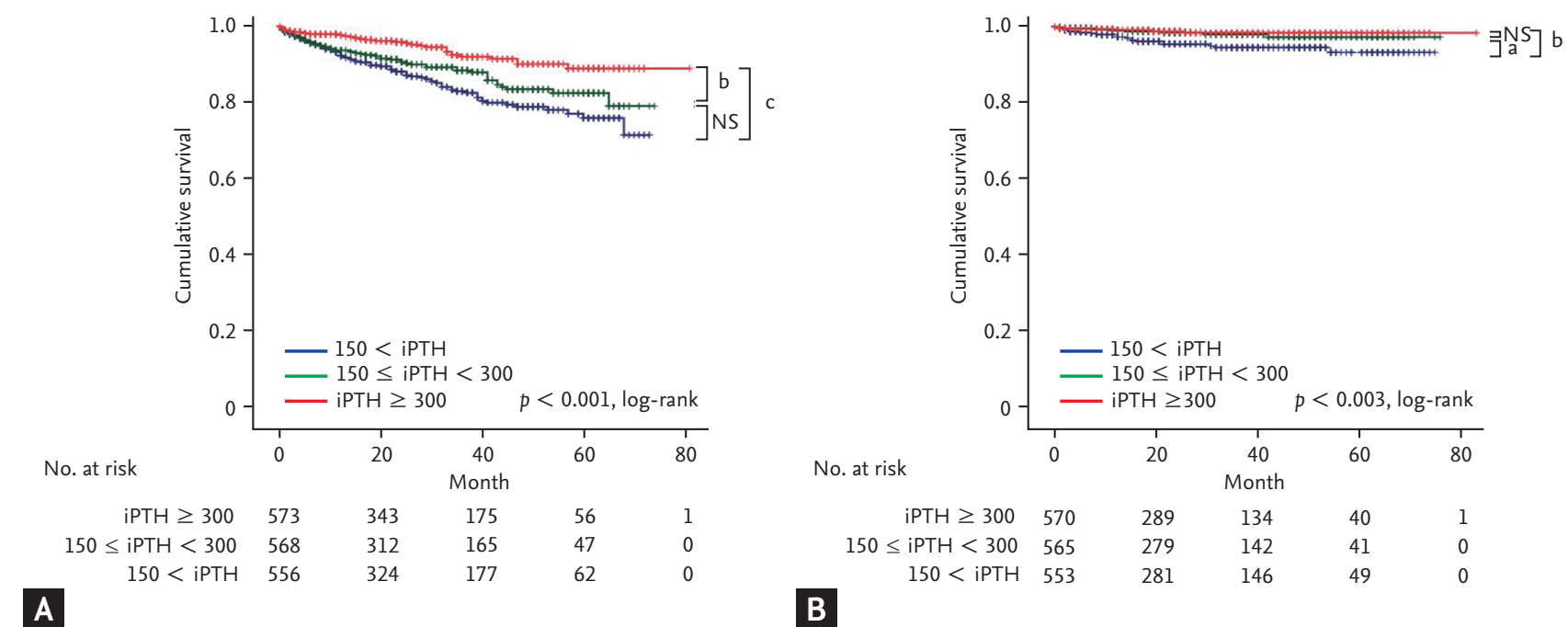

Figure 2. Kaplan-Meier survival curve for (A) all-cause and (B) and infection-related mortality according to the levels of serum intact parathyroid hormone (iPTH) levels. NS, non-specific. ${ }^{a} p<0.05,{ }^{b} p<0.01$, and ${ }^{c} p<0.001$.

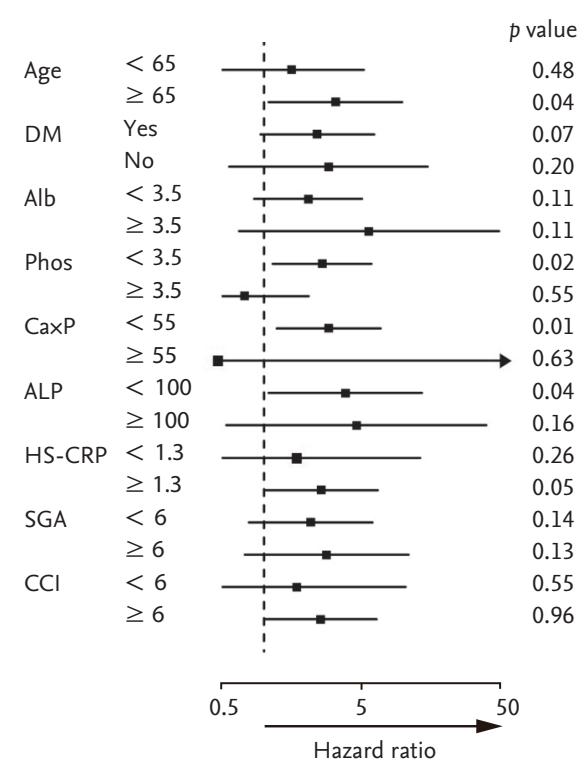

Figure 3. Hazard ratio ( $95 \%$ confidence interval) for infection-related mortality associated with lower serum intact parathyroid hormone (iPTH) levels $(<150 \mathrm{pg} / \mathrm{mL})$ in subgroups of dialysis patients. DM, diabetes mellitus; Alb, albumin; Phos, phsophorus; $\mathrm{Ca} \times \mathrm{P}$, calcium $\times$ phosphorus product; ALP, alkaline phosphatase; hs-CRP, high sensitive C-reactive protein; SGA, subjective global assessment; CCI, Charlson comorbidity index.

regression analyses for all-cause and infection-related mortality according to serum iPTH level at baseline. In univariate Cox regression analysis, the HR for all-cause mortality of patients with low serum iPTH level was 1.34
(95\% CI, 0.96 to $1.87 ; p=0.09$ ), and that of patients with high serum iPTH level was 0.53 (95\% CI, 0.35 to $0.81 ; p=$ 0.003 ) when patients with target serum iPTH level (150 to $300 \mathrm{pg} / \mathrm{mL}$ ) were used as the reference category. The HR for infection-related mortality in a crude model of patients with low serum iPTH level was 2.61 (95\% CI, 1.16 to $5.89 ; p=0.02$ ), and that of patients with high serum iPTH level was 0.73 (95\% CI, 0.25 to $2.10 ; p=0.55$ ) when patients with target serum iPTH level (150 to 300 $\mathrm{pg} / \mathrm{mL}$ ) were used as the reference category.

In the multivariable analysis, high or low serum iPTH level was not associated with increased all-cause mortality in model 1 (serum iPTH < $150 \mathrm{pg} / \mathrm{mL}$ [HR, 0.81; 95\% CI, 0.58 to 1.13; $p=0.22$ ], serum iPTH $>300 \mathrm{pg} / \mathrm{mL}$ [HR, 0.68 ; 95\% CI, 0.44 to 1.05 ; $p=0.08$ ]) or model 2 (serum iPTH < $150 \mathrm{pg} / \mathrm{mL}$ [HR, 1.1; 95\% CI, 0.74 to $1.61 ; p=$ 0.65], serum iPTH > $300 \mathrm{pg} / \mathrm{mL}$ [HR, 0.95; 95\% CI, 0.58 to $1.58 ; p=0.87]$ ) after adjustment for age, sex, DM, CAD, malignancy, HIV infection, BMI, systolic BP, diastolic BP, modified Charlson comorbidity index, hemoglobin, creatinine, albumin, potassium, corrected calcium, phosphorus, alkaline phosphatase, hs-CRP, and SGA. However, multivariate Cox regression analysis showed that patients with serum iPTH $<150 \mathrm{pg} / \mathrm{mL}$ remained at higher risk for infection-related mortality than those within the target range of serum iPTH after adjusting for confounding variables (model 1 [serum iPTH < 150 $\mathrm{pg} / \mathrm{mL}$ : HR, 2.61; 95\% CI, 1.16 to $5.89 ; p=0.02$; serum 
iPTH > $300 \mathrm{pg} / \mathrm{mL}$ : HR, 0.92; 95\% CI, 0.31 to $2.74 ; p=$ 0.89] and model 2 [serum iPTH < $150 \mathrm{pg} / \mathrm{mL}$ : HR, 2.52; 95\% CI, 1.06 to 5.99; $p=0.04$; serum iPTH > $300 \mathrm{pg} / \mathrm{mL}$ : HR, 1.08; 95\% CI, 0.31 to $3.74 ; p=0.90]$ ) after adjustment for age, sex, DM, CAD, malignancy, HIV infection, BMI, systolic BP, diastolic BP, modified Charlson comorbidity index, hemoglobin, creatinine, albumin, potassium, corrected calcium, phosphorus, alkaline phosphatase, hs-CRP, and SGA.

\section{Subgroup analysis of infection-related mortality by risk factors according to serum iPTH level}

The results of subgroup analysis exploring associations between serum iPTH level and infection-related mortality in various subgroups of patients are displayed in Fig. 3. In subgroup analysis, there were no significant interactions between low serum iPTH level and DM, serum albumin, hs-CRP, SGA, and comorbidity index in infection-related mortality. However, there was a tendency for significant interactions to exist between low serum iPTH level and age ( $<65$ or $\geq 65$ year), serum phosphorus $(\mathrm{P}<3.5$ or $\mathrm{P} \geq 3.5 \mathrm{mg} / \mathrm{dL}), \mathrm{Ca} \times \mathrm{P}$ product $(\mathrm{Ca}$ $\times \mathrm{P}<55$ or $\mathrm{Ca} \times \mathrm{P} \geq 55)$, and serum ALP (ALP $<100 \mathrm{IU}$ or ALP $\geq 100$ ). The HR of infection-related mortality in the low serum iPTH group was significantly higher in patients with lower serum phosphorus, $\mathrm{Ca} \times \mathrm{P}$ product, and serum ALP and was substantially higher in patients older than 65 years compared with those 65 years and younger.

\section{DISCUSSION}

The results of our study clearly demonstrated that low iPTH level was associated with increased risk of allcause and infection-related mortality in incident dialysis patients. Infection-related mortality was especially increased in patients with low serum iPTH level even after adjustment of confounding factors. These findings suggest that low serum iPTH level is an independent risk factor for infection-related mortality in incident dialysis patients.

The relationship between serum iPTH level and allcause mortality in dialysis patients is still controversial. Most epidemiologic studies have suggested that the association between iPTH and all-cause mortality in dialysis patients is U-shaped [12-15]. Some other researches indicate that there is no correlation between serum iPTH level and mortality risk $[1,4,16]$. In the present study, low serum iPTH level (serum iPTH $<150$ $\mathrm{pg} / \mathrm{mL}$ ) was associated with highest mortality rates, and high serum iPTH level (serum iPTH $\geq 300 \mathrm{pg} / \mathrm{mL}$ ) was associated with lowest mortality rates in incident dialysis patients. This discrepancy between the current study and previous studies may be due to differences in study design, follow-up period, and timing of iPTH measurement.

Our observations are of importance as this is the first prospective observational study about infection-related outcomes of incident dialysis patients according to serum iPTH level in the Korean population. To date, no epidemiologic study about the relationship between serum iPTH level and infection-related mortality has been published. Although the follow-up period was short, enrolled participants formed a relatively homogenous group within 3 months of starting dialysis. Thus, it seems that our study group is more suitable to evaluate the impact of low iPT'H level on infection in dialysis patients. Another interesting finding of this study is that patients with low serum iPTH level had poorer survival in infection-related death than those with serum iPTH level in the target range, whereas survival rates for all-cause death were not different between patients with low serum iPTH level and those with target range of serum iPTH level, as shown in Table 4, Fig. 1. This finding means that serum iPTH level at the time of starting dialysis is more meaningful in infection-related mortality than all-cause mortality. Further long-term study is needed to evaluate the impact of serum iPTH level on infection- related mortality in dialysis patients.

The results of our study suggest that low serum iPTH level increases the susceptibility of dialysis patients to infection, but the pathophysiologic mechanisms are not well established. For this, we speculate possible mechanisms. First, PTH had a stimulatory function on $\mathrm{T}$ lymphocytes, and low iPTH might be associated with decrease in cellular immunity. Previous studies demonstrated that iPTH stimulated proliferation of T lymphocytes and increased interleukin-2 (IL-2) production in human peripheral blood mononuclear cells (PBMCs) and rat PBMCs in a 5/6 nephrectomy model, and PTH inactivation by treatment of acetic acid or parathyroid- 
ectomy abolished T lymphocyte stimulation $[17,18]$. Furthermore, human $\mathrm{CD}_{4} / \mathrm{CD} 8$ ratio was significantly lower in prevalent HD patients with serum iPTH level below $65 \mathrm{pg} / \mathrm{mL}$ than in those with PTH level greater than 300 $\mathrm{pg} / \mathrm{mL}$, suggesting an immunosuppressive status associated with low serum iPTH [19]. Second, low serum iPTH level is related to malnutrition-inflammation-complex syndrome (MICS) [20]. Low serum iPTH level reflects a state of malnutrition, which may increase infection risk [21], and inflammation suppresses PTH secretion, and low PTH induces inflammation [22,23]. One long-term observational study reported that PTH is directly correlated with serum albumin, serum creatinine, and serum phosphorus and was correlated inversely with age and serum calcium [6]. In our study, low serum iPTH level combined with serum phosphorus level lower than 3.5 g/dL or with $\mathrm{Ca} \times \mathrm{P}$ product lower than 55 was related to significantly increased infection-related mortality in subgroup analysis. Among the biochemical parameters of CKD-MBD, hypophosphatemia reflects poor nutritional status and has been reported as an independent predictor for all-cause mortality in dialysis patients $[13,15,24]$. Therefore, low serum iPTH level combined with low serum phosphorus is a strong indicator of malnutrition and may have a deleterious effect on infection in dialysis patients. This suggests that malnutrition has a strongly detrimental effect due to increased risk of infection in incident dialysis patients.

We also demonstrated that low serum iPTH level combined with serum ALP level lower than 100 IU/L was related to significantly increased infection-related mortality in subgroup analysis. Most epidemiologic studies showed that serum ALP level has a linear and incremental association with all-cause mortality in pre-dialysis and dialysis patients [25-27]. However, the relationship between serum ALP level and infection-related mortality has not been elucidated. Low serum ALP could also be indicative of low-turnover bone disease. Adynamic bone disease is characterized by markedly low bone turnover, reducing osteoanabolic stimulation caused by oversuppression of $\mathrm{PTH}$. In clinical practice, the combination of low iPTH and low bone ALP levels may be suggestive of adynamic bone disease in lieu of histomorphometric analysis of bone biopsies [28]. One study suggested that adynamic bone disease is a surrogate marker of MICS and increased mortality associated with adynamic bone disease is caused by MICS [29]. Hence, clinicians should attend more carefully to controlling low serum iPTH level in high-risk patients, such as patients with hypophosphatemia, low $\mathrm{Ca} \times \mathrm{P}$ product, and low serum ALP level.

Immune dysfunction is a characteristic of advanced CKD, and infection is a frequent cause of mortality in ESRD. Mortality rates due to sepsis in dialysis patients are several hundred times higher than those observed in the general population [7]. Traditionally, uremic toxins, comorbidity conditions, anemia, and malnutrition are responsible for innate and adaptive immune dysfunction in CKD [30,31]. However, recent studies have also highlighted implications for biochemical parameters of CKD-MBD regarding infection that extend beyond mineral homeostasis and bone metabolism. An observational study, the Dialysis Outcomes and Practice Patterns Study (DOPPS), found that elevated serum ALP level was associated with higher risk of infection-related death in HD patients, independent of calcium, phosphorus, and iPTH levels [25]. Two recent multicenter prospective studies in Korea also showed that elevated serum ALP level and low serum phosphorus level were independently associated with higher risk of infection-related mortality in dialysis patients $[32,33]$. To the best of our knowledge, the present study is the first multicenter prospective study showing significant associations between serum iPTH level and mortality risk of infection, rather than cardiovascular disease, in incident dialysis patients.

There are some limitations of the present study. First, we did not analyze the impacts of therapeutic interventions for CKD-MBD on infection-related mortality. Second, we did not assess other biochemical markers related to CKD-MBD, such as fibroblast growth factor-23 or vitamin $\mathrm{D}$ metabolites. Third, we cannot exclude residual confounding given the observational study design. Fourth, we did not perform bone biopsy and so cannot determine whether low-turnover bone disease itself increased the infection-related mortality in the low serum iPTH level. Last, the number of patients who were dropped out from the study for reasons other than death was relatively high. This may be due to the high percentage of patients with 'transfer to a nonparticipating hospital ( $\mathrm{n}=282,39.0 \%$ )' and 'kidney transplantation ( $n=125,17.3 \%)$.' In Korea, creation of vascular access and 
initiation of HD are performed at university hospitals or general hospitals, but maintenance HD is usually performed at private clinics. In addition, enrolled patients were incident dialysis patients, and a considerable number of patients received kidney transplantation during the follow up period. Despite these limitations, our study clearly demonstrates the clinical significance of low serum iPTH for infection-related mortality in incident dialysis patients.

In conclusion, this prospective cohort study found that low serum iPTH level was associated with increased risk of subsequent infection in incident dialysis patients. This association suggests that serum iPTH level is an independent risk factor for infection.

\section{KEY MESSAGE}

1. Low serum intact parathyroid hormone (iPTH) level is an independent risk factor for infection-related mortality in incident dialysis patients.

2. Infection-related mortality in the subgroup analysis of incident dialysis patients with low serum iPTH level was significantly high in patients with lower serum phosphorus, Ca $\times$ $P$ product, and serum alkaline phosphatase and was substantially higher in patients older than 65 years compared with those 65 years and younger.

3. The pathophysiologic mechanisms between low serum iPTH level and infection susceptibility in dialysis patients can be suggested that low iPTH might be associated with decrease in cellular immunity and related to malnutrition-inflammation-complex syndrome.

\section{Conflict of interest}

No potential conflict of interest relevant to this article was reported.

\section{Acknowledgments}

This research was supported by a grant of the Korea Health Technology R\&D Project through the Korea Health Industry Development Institute (KHIDI), funded by the Ministry of Health and Welfare, Republic of
Korea (grant number: HC15C1129). This work was supported by the National Research Foundation of Korea (NRF) grant funded by the Ministry of Science and ICT, Republic of Korea (grant number: 2018R1C1B5045006).

\section{REFERENCES}

1. Block GA, Klassen PS, Lazarus JM, Ofsthun N, Lowrie EG, Chertow GM. Mineral metabolism, mortality, and morbidity in maintenance hemodialysis. J Am Soc Nephrol 2004;15:2208-2218.

2. Kimata N, Albert JM, Akiba T, et al. Association of mineral metabolism factors with all-cause and cardiovascular mortality in hemodialysis patients: the Japan dialysis outcomes and practice patterns study. Hemodial Int 2007;11:340-348.

3. Young EW, Albert JM, Satayathum S, et al. Predictors and consequences of altered mineral metabolism: the Dialysis Outcomes and Practice Patterns Study. Kidney Int 2005;67:1179-1187.

4. Noordzij M, Korevaar JC, Bos WJ, et al. Mineral metabolism and cardiovascular morbidity and mortality risk: peritoneal dialysis patients compared with haemodialysis patients. Nephrol Dial Transplant 2006;21:2513-2520.

5. Kim Y, Yoo KD, Kim HJ, et al. Association of serum mineral parameters with mortality in hemodialysis patients: data from the Korean end-stage renal disease registry. Kidney Res Clin Pract 2018;37:266-276.

6. Avram MM, Mittman N, Myint MM, Fein P. Importance of low serum intact parathyroid hormone as a predictor of mortality in hemodialysis and peritoneal dialysis patients: 14 years of prospective observation. Am J Kidney Dis 2001;38:1351-1357.

7. Sarnak MJ, Jaber BL. Mortality caused by sepsis in patients with end-stage renal disease compared with the general population. Kidney Int 2000;58:1758-1764.

8. Alexiewicz JM, Smogorzewski M, Fadda GZ, Massry SG. Impaired phagocytosis in dialysis patients: studies on mechanisms. Am J Nephrol 1991;11:102-111.

9. Perry HM 3rd, Chappel JC, Bellorin-Font E, Tamao J, Martin KJ, Teitelbaum SL. Parathyroid hormone receptors in circulating human mononuclear leukocytes. J Biol Chem 1984;259:5531-5535.

10. Hwang E, Choi BS, Oh KH, Kwon YJ, Kim GH. Management of chronic kidney disease-mineral and bone disor- 
der: Korean working group recommendations. Kidney Res Clin Pract 2015;34:4-12.

11. National Kidney Foundation. K/DOQI clinical practice guidelines for bone metabolism and disease in chronic kidney disease. Am J Kidney Dis 2003;42(4 Suppl 3):S1S2O1.

12. Li D, Zhang L, Zuo L, Jin CG, Li WG, Chen JB. Association of CKD-MBD markers with all-cause mortality in prevalent hemodialysis patients: a cohort study in Beijing. PLoS One 2017;12:e0168537.

13. Naves-Diaz M, Passlick-Deetjen J, Guinsburg A, et al. Calcium, phosphorus, PTH and death rates in a large sample of dialysis patients from Latin America. The CORES Study. Nephrol Dial Transplant 2011;26:1938-1947.

14. Fernandez-Martin JL, Martinez-Camblor P, Dionisi MP, et al. Improvement of mineral and bone metabolism markers is associated with better survival in haemodialysis patients: the COSMOS study. Nephrol Dial Transplant 2015;30:1542-1551.

15. Floege J, Kim J, Ireland E, et al. Serum iPTH, calcium and phosphate, and the risk of mortality in a European haemodialysis population. Nephrol Dial Transplant 2011;26:1948-1955.

16. Wald R, Sarnak MJ, Tighiouart H, et al. Disordered mineral metabolism in hemodialysis patients: an analysis of cumulative effects in the hemodialysis (HEMO) Study. Am J Kidney Dis 2008;52:531-540.

17. Klinger M, Alexiewicz JM, Linker-Israeli M, et al. Effect of parathyroid hormone on human T cell activation. Kidney Int 1990;37:1543-1551.

18. Lewin E, Ladefoged J, Brandi L, Olgaard K. Parathyroid hormone dependent $\mathrm{T}$ cell proliferation in uremic rats. Kidney Int 1993;44:379-384.

19. Ozdemir FN, Yakupoglu U, Turan M, et al. Role of parathormone levels on T-cell response in hemodialysis patients. Transplant Proc 2002;34:2044-2045.

20. Dukkipati R, Kovesdy CP, Colman S, et al. Association of relatively low serum parathyroid hormone with malnutrition-inflammation complex and survival in maintenance hemodialysis patients. J Ren Nutr 2010;20:243-254.

21. Fukagawa M, Akizawa T, Kurokawa K. Is aplastic osteodystrophy a disease of malnutrition? Curr Opin Nephrol Hypertens 2000;9:363-367.

22. Carlstedt E, Ridefelt P, Lind L, Rastad J. Interleukin-6 induced suppression of bovine parathyroid hormone secretion. Biosci Rep 1999;19:35-42.

23. Nielsen PK, Rasmussen AK, Butters R, et al. Inhibition of PTH secretion by interleukin-1 beta in bovine parathyroid glands in vitro is associated with an up-regulation of the calcium-sensing receptor mRNA. Biochem Biophys Res Commun 1997;238:880-885.

24. Kalantar-Zadeh K, Kuwae N, Regidor DL, et al. Survival predictability of time-varying indicators of bone disease in maintenance hemodialysis patients. Kidney Int 2006;70:771-780.

25. Blayney MJ, Pisoni RL, Bragg-Gresham JL, et al. High alkaline phosphatase levels in hemodialysis patients are associated with higher risk of hospitalization and death. Kidney Int 2008;74:655-663.

26. Kovesdy CP, Ureche V, Lu JL, Kalantar-Zadeh K. Outcome predictability of serum alkaline phosphatase in men with pre-dialysis CKD. Nephrol Dial Transplant 2010;25:3003-3011.

27. Kalantar-Zadeh K, Shah A, Duong U, Hechter RC, Dukkipati R, Kovesdy CP. Kidney bone disease and mortality in CKD: revisiting the role of vitamin $\mathrm{D}$, calcimimetics, alkaline phosphatase, and minerals. Kidney Int Suppl 2010;117:S10-S21.

28. Bover J, Urena P, Brandenburg V, et al. Adynamic bone disease: from bone to vessels in chronic kidney disease. Semin Nephrol 2014;34:626-640.

29. Heaf J. Adynamic bone disease and malnutrition-inflammation-cachexia syndrome. Kidney Int 2007;71:1326

30. Hauser AB, Stinghen AE, Kato S, et al. Characteristics and causes of immune dysfunction related to uremia and dialysis. Perit Dial Int 2008;28 Suppl 3:S183-S187.

31. Dalrymple LS, Go AS. Epidemiology of acute infections among patients with chronic kidney disease. Clin J Am Soc Nephrol 2008;3:1487-1493.

32. Hwang SD, Kim SH, Kim YO, et al. Serum alkaline phosphatase levels predict infection-related mortality and hospitalization in peritoneal dialysis patients. PLoS One 2016;11:e0157361.

33. Lee JE, Lim JH, Jang HM, et al. Low serum phosphate as an independent predictor of increased infection-related mortality in dialysis patients: a prospective multicenter cohort study. PLoS One 2017;12:e0185853. 


\section{Supplementary Material 1. Ethics}

The study was approved by the Institutional Review Board at each center (The Catholic University of Korea, Bucheon St. Mary's Hospital; The Catholic University of Korea, Incheon St. Mary's Hospital; The Catholic University of Korea, Seoul St. Mary's Hospital; The Catholic University of Korea, St. Mary's Hospital; The Catholic University of Korea, St. Vincent's Hospital; The Catholic University of Korea, Uijeongbu St. Mary's Hospital; Cheju Halla General Hospital; Chonbuk National University Hospital; Chonnam National University Hospital; Chung-Ang University Medical Center; Chungbuk National University Hospital; Chungnam National University Hospital; Dong-A University Medical
Center; Ehwa Womens University Medical Center; Fatima Hospital; Gachon University Gil Medical Center; Inje University Pusan Paik Hospital; Kyungpook National University Hospital; Kwandong University College of Medicine, Myongji Hospital; National Health Insurance Corporation Ilsan Hospital; National Medical Center; Pusan National University Hospital; Samsung Medical Center, Seoul; Seoul Metropolitan Government, Seoul National University, Boramae Medical Center; Seoul National University Hospital; Seoul National University, Bundang Hospital; Yeungnam University Medical Center; Yonsei University, Severance Hospital; Yonsei University, Gangnam Severance Hospital; Ulsan University Hospital; Wonju Christian Hospital [in alphabetical order]). 